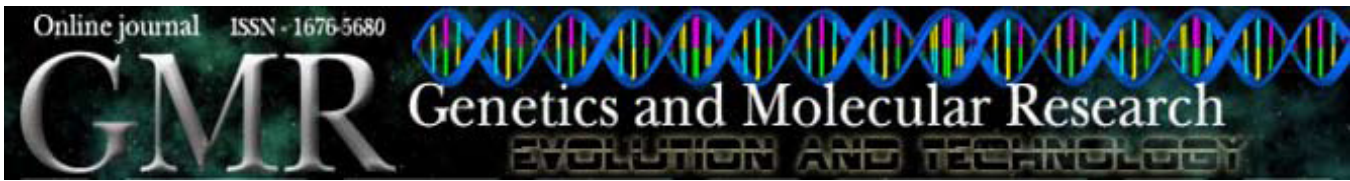

\title{
A proposed selection index for feedlot profitability based on estimated breeding values
}

\author{
R.R. van der Westhuizen and J. van der Westhuizen \\ ARC-Animal Production Institute, Irene, South Africa \\ Corresponding author: R.R. van der Westhuizen \\ E-mail: bobbie@arc.agric.za
}

Genet. Mol. Res. 8 (2): 448-455 (2009)

Received February 21, 2009

Accepted March 9, 2009

Published April 22, 2009

\begin{abstract}
It is generally accepted that feed intake and growth (gain) are the most important economic components when calculating profitability in a growth test or feedlot. We developed a single post-weaning growth (feedlot) index based on the economic values of different components. Variance components, heritabilities and genetic correlations for and between initial weight (IW), final weight (FW), feed intake (FI), and shoulder height (SHD) were estimated by multitrait restricted maximum likelihood procedures. The estimated breeding values (EBVs) and the economic values for IW, FW and FI were used in a selection index to estimate a post-weaning or feedlot profitability value. Heritabilities for IW, FW, FI, and SHD were $0.41,0.40,0.33$, and 0.51 , respectively. The highest genetic correlations were 0.78 (between IW and FW) and 0.70 (between FI and FW). EBVs were used in a selection index to calculate a single economical value for each animal. This economic value is an indication of the gross profitability value or the gross test value (GTV) of the animal in a post-weaning growth test. GTVs varied between -R192.17 and R231.38 with an average of R9.31 and a standard deviation of R39.96. The Pearson correlations between EBVs (for production and efficiency traits) and GTV ranged from -0.51 to 0.68 . The lowest correlation (closest to zero) was 0.26 between the Kleiber ratio and GTV. Correlations of 0.68 and -0.51 were estimated between average daily gain and GTV and feed conversion ratio and GTV, respectively. These results showed that it is possible to select for
\end{abstract}


GTV. The selection index can benefit feedlotting in selecting offspring of bulls with high GTVs to maximize profitability.

Key words: Beef cattle; Feed intake; Genetic (co)variances

\section{INTRODUCTION}

Variable costs in post-weaning growth and finishing cattle in a feedlot play a major role in the ultimate profitability of beef production. It is therefore important that the biological differences among animals be exploited and individuals identified that can be used as parent stock to increase the biological and ultimately economic efficiency of feedlot animals.

The perspective should, however, always be that the efficiency of the cow, as the basis of beef production, cannot be compromised as she consumes between 70 and $94 \%$ of the energy required until weaning her calf. Even when the total digestible nutrients consumed are traced to marketing age, after feedlotting of the calf, the cow still consumes between 56 and $70 \%$ thereof (Ferrell and Jenkins, 1984; Urick et al., 1984; Van Oijen et al., 1992). Slaughter stock, however, usually consume expensive feed, particularly those finished on high concentrate feedlot diets.

Despite manipulation of the environment and cattle management to reduce feed costs, it has also been known for several decades that feed intake and measures of feed efficiency are heritable in beef cattle. Dickerson (1978) also stated that biological inputs (e.g., feed intake) are only worth considering if associated with an expense. Water is a major "biological" input into animal production systems, yet is seldom considered in efficiency studies due to its relatively low costs. Therefore, it is accepted that feed intake and growth (gain) are the most important economic components when calculating profitability in a growth test or feedlot. The inclusion of feed intake and gain information in selection decisions would facilitate genetic improvement of efficiency and profitability of beef cattle production. In order to include efficiency of feed intake and gain information in selection decisions, appropriate measurements of these traits are required.

Feed intake and growth (gain) are measured in centralized growth tests of the Agricultural Research Council (ARC) in South Africa. The problem, however, is to use these data in an appropriate way when selection decisions are made so as to select the most profitable feedlot animals.

Profitability is a composite trait involving a number of component traits (Dickerson, 1969). Therefore, an appropriate way to define a post-weaning profitability value or feedlot growth profitability value could be by means of a selection index, which includes the major components determining profitability (e.g., feed intake and gain) as well as their relative economic values.

The aim of this study was 1) to estimate genetic parameters for initial weight (IW), final weight (FW), feed intake (FI), and shoulder height (SHD) of Bonsmara bulls, 2) to derive an index (gross test value; GTV) of weights and feed intake that is associated with profitability of fed cattle, and 3) to evaluate associations between GTV and phenotypes for which estimated breeding values (EBVs) are currently produced.

\section{MATERIAL AND METHODS}

The data analyzed in this study were collected from the centralized growth test stations of the ARC. Bulls are sent to one of the ARC central testing stations where live weights and individual feed intake are recorded weekly. 
On arrival, bulls go through a 4-week adaptation period to gradually adapt to the feed ration. The growth test was originally 20 weeks long. In 1990, it was shortened to a 16-week test period and in 1999 to a 12-week test period, as recommended by Archer and Bergh (2000).

Data from Bonsmara bulls, assessed in these growth tests between 1970 and 2001, were used in this study.

During this period 11,839 Bonsmara bulls were tested.

The dataset to estimate genetic variance components consisted of the individual feed intake and weight recordings of 6995 Bonsmara bulls tested between 1990 and 2001. The pedigree file represented 26,076 animals with 3555 sires and 15,783 dams.

The importance of non-genetic sources of variation in the traits was determined by the PROC GLM procedure of SAS (2000). Non-genetic sources (at a significance level of P $<0.001)$ that were included in the models for IW, FW and SHD were the linear regression of the age of the dam, the linear and quadratic regression of the age of the animal at the end of the growth test and the contemporary group (fixed) effect for the growth test (which includes test center, test year and test number) (524 levels). The linear regression of the age of the dam was not significant for feed intake, and therefore, only the linear and quadratic regression of the age of the animal at the end of the growth test and the contemporary group fixed effect for the growth test were included in the final model.

Variance components, heritabilities and genetic correlations for and between IW, FW, FI during the test period, and SHD were estimated by a multitrait restricted maximum likelihood procedure using the VCE package developed by Groeneveld (1994). Shoulder height was included in the multitrait analysis to account for differences in mature size (maturity types) among bulls. This should enable breeders to also select economically fast growers with a small frame size whose daughters could be used as replacement heifers.

The following model was used for the analysis:

$$
\mathrm{y}=\mathrm{Xb}+\mathrm{Za}+\mathrm{e},
$$

(Equation 1)

where: $y=$ vector of the observations for the $\mathrm{i}^{\text {th }}$ trait, $\mathrm{b}=$ vector of fixed effects for the $\mathrm{i}^{\text {th }}$ trait, $\mathrm{a}=$ vector of random animal effects for the $\mathrm{i}^{\text {th }}$ trait, $\mathrm{e}=$ vector of random residual effects for the $i^{\text {th }}$ trait, $X$ and $\mathrm{Z}$ are incidence matrices relating records of the $i^{\text {th }}$ trait to fixed and random animal effects, respectively.

After variance components were estimated, the components were used to predict breeding values using the same model for each animal for the different traits. These EBVs were then used in a selection index to calculate a single economical value, or a GTV, for each animal. This economical value is an indication of the gross profitability of the animal in a post-weaning growth test.

It is generally accepted that the selection index is, in most cases, the most accurate method to use. The optimal procedure for selection uses all the information available about each individual's breeding value, combined into an index of merit (Falconer and Mackay, 1996). The aim of a selection index is to combine all relevant information into a single numeric value on the basis of which individuals will be selected. The construction of an index is not easy without the use of matrix methods, particularly if there are more than two sources of information (Nicholas, 1987; Van Vleck, 1993). Lerner (1961) also stated that the accuracy of 
the selection index, as compared to an independent culling level procedure, improves as the number of traits in the selection index increases.

This selection index (based on EBVs) differs from the classic Smith-Hazel selection index method in the sense that in the classic index phenotypic values are used to calculate the relevant b-values, which also include the correlations between the relative traits. In the constructed selection index in the current study, a multitrait animal model was used to calculate breeding values. As all genetic covariances among traits were taken into account in the breeding value predictions, the drafting of the selection index for each animal was thus simply a function of the economic value of each trait.

The following selection index was used to calculate the GTV for each animal:

GTV $($ in South African Rand $)=\left(\left(\left(\mathrm{EBV}_{\mathrm{FW}} \times 12.35\right) \times 55 \%\right)-\left(\mathrm{EBV}_{\mathrm{IW}} \times 8.25\right)\right)-\left(\mathrm{EBV}_{\mathrm{FI}} \times \mathrm{R} 0.90\right)$ (Equation 2)

where $\mathrm{EBV}_{\mathrm{FW}}=$ estimated breeding value of final weight, $\mathrm{EBV}_{\mathrm{IW}}=$ estimated breeding value of initial weight, $\mathrm{EBV}_{\mathrm{FI}}=$ estimated breeding value of feed intake.

The following assumptions were made in order to calculate the GTV:

- Live weight weaner calf price at R8.25 per kilogram

- A3 carcass price of R12.35 per kilogram (it is assumed that all bulls are classified as A3)

- Dressing percentage at $55 \%$

- Feed cost set at R0.90 per kilogram.

In order to test the normality of the distribution of GTV, the skewness and kurtosis statistics for GTV were obtained using the PROC MEANS procedure of SAS (2000).

To show the genetic changes of GTV over years, a genetic trend was estimated. The genetic trend is the average GTV value per year of all measured animals born in that specific year.

\section{RESULTS AND DISCUSSION}

Table 1 presents the general statistics (for the 6995 animals in the edited dataset) for the different traits and covariances included in the different models for the estimation of variance components, heritabilities and genetic correlations.

\begin{tabular}{|c|c|c|c|c|}
\hline Trait & Minimum & Maximum & Average & SD \\
\hline IW (kg) & 139 & 414 & 260.19 & 32.21 \\
\hline FW (kg) & 232 & 585 & 438.12 & 42.72 \\
\hline $\mathrm{FI}(\mathrm{kg})$ & 433 & 1685 & 1022.96 & 137.50 \\
\hline SHD (mm) & 1050 & 1580 & 1188.28 & 33.81 \\
\hline Age (days) & 272 & 410 & 357.76 & 26.81 \\
\hline Dam age (days) & 669 & 5493 & 2162.90 & 1013.90 \\
\hline
\end{tabular}


The average age of the animals at the end of the growth test was 357.8 days. The youngest animal was 272 days old while the oldest animal was 410 days (a difference of 138 days). The age of the dams varied from one year and 10 months (669 days) to 15 years, with an average of 6 years of age (Table 1).

Table 1 also shows that the weight of the animals at the onset of the growth tests varied between 139 and $414 \mathrm{~kg}$ with an average of $260.2 \mathrm{~kg}$ and a standard deviation of $32.2 \mathrm{~kg}$. The minimum and maximum weight of animals at the end of the growth tests were 232 and $585 \mathrm{~kg}$ with an average of $438.12 \mathrm{~kg}$.

Table 2 presents the heritability and genetic correlation estimates for and between the different traits. The heritabilities obtained for IW and FW were 0.41 and 0.40 , respectively, with a genetic correlation of 0.78 between them. These estimates are slightly higher than those reported by Koots et al. (1994a) for weaning and yearling weights of 0.27 and 0.35 , respectively. The reason for these higher heritabilities compared to that of Koots et al. (1994a) could be due to the inclusion of the maternal effects in both weaning and yearling weights. In this study, the maternal effects on weights were ignored. The genetic correlation estimate between IW and FW of 0.78 obtained in this study is exactly the same as the value between weaning and yearling weights that was determined by Koots et al. (1994b).

\begin{tabular}{|c|c|c|c|c|}
\hline Trait & IW & FW & FI & SHD \\
\hline Initial weight (IW) & $0.41 \pm 0.02$ & $0.78 \pm 0.02$ & $0.41 \pm 0.05$ & $0.40 \pm 0.03$ \\
\hline Final weight (FW) & & $0.40 \pm 0.02$ & $0.70 \pm 0.03$ & $0.55 \pm 0.03$ \\
\hline Feed intake (FI) & & & $0.33 \pm 0.02$ & $0.39 \pm 0.04$ \\
\hline Shoulder height (SHD) & & & & $0.51 \pm 0.02$ \\
\hline
\end{tabular}

The heritability of 0.33 for FI corresponds to the heritabilities published elsewhere in the literature (Archer et al., 1998; Herd and Bishop, 2000). Koots et al. (1994a), however, presented a heritability of 0.41 for feed intake. Koots et al. (1994b) presented genetic correlations of 0.67 (between FI and weaning weight), 0.79 (between FI and yearling weight) and 0.38 (between FI and yearling height). Besides the higher average correlation of 0.67 between FI and weaning weight obtained by Koots et al. (1994b) (compared to the correlation of 0.41 between FI and IW obtained in this study), the correlations between FI and IW and between FI and SHD correspond well to the correlations between FI and yearling weight and between FI and yearling height reported by Koots et al. (1994b).

The genetic correlation between FI and FW of 0.70 was higher than the correlation of 0.41 between FI and IW. The heritability of 0.51 for SHD corresponds to heritabilities obtained by the Animal Improvement Institute of the ARC for ten different breeds (Anonymous, 1999).

After fitting the appropriate models, using the estimated genetic (co)variances, best linear unbiased prediction (BLUP) breeding values (EBVs) were obtained for each animal. These EBVs were then used in the selection index to calculate the GTV for each bull. Figure 1 presents the distribution of GTVs. 


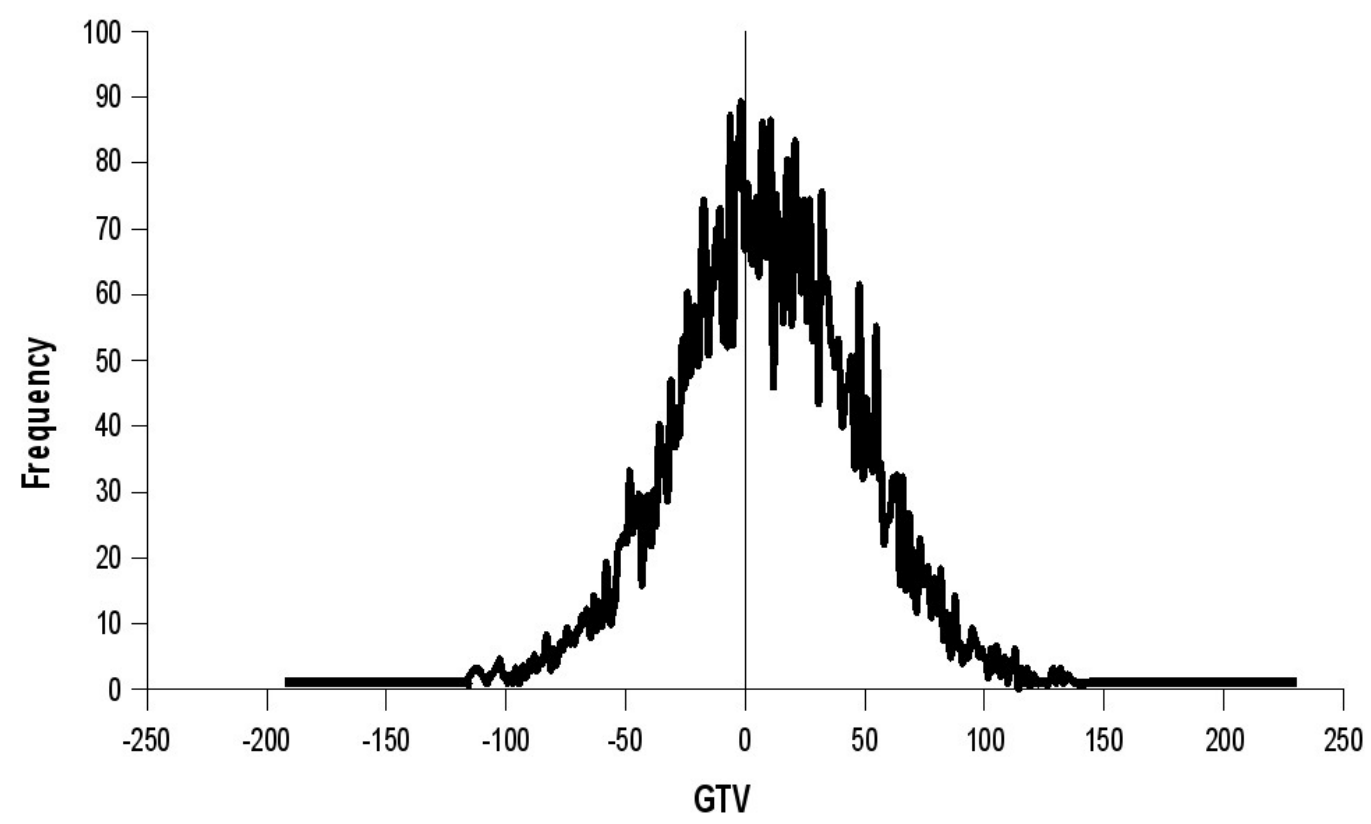

Figure 1. Frequency distribution of gross test value (GTV) in South African Rand.

The skewness statistic for this distribution is 0.017 while the standard error of skewness is 0.0293 . Since two times the standard error of skewness is greater than the absolute value for the skewness statistic, the distribution is not significantly skewed. The data are, however, leptokurtic ("taller" than a normally distributed population) due to a positive ( 0.845 $\pm 0.059)$ kurtosis statistic. Although the data are leptokurtic, it was assumed that GTVs are normally distributed. The GTVs varied between -R192.17 and R231.38 with an average of R9.31 and a standard deviation of R39.96. The coefficient of variation for GTV was 4.29\% indicating that there is variation in this trait and that it can be selected for.

Table 3 presents the simple Pearson correlations between the individual GTVs and corresponding EBVs of average daily gain (ADG), SHD, Kleiber ratio (KLB), feed conversion ratio (FCR), and weaning weight, obtained from the 2002 national BLUP analysis for the Bonsmara breed.

Table 3. Pearson correlations between gross test values (GTV) and other production traits.

\begin{tabular}{lc}
\hline Production/reproductive trait & Pearson correlation with GTV \\
\hline Average daily gain & 0.68 \\
Shoulder height & 0.29 \\
Kleiber ratio & 0.26 \\
Feed conversion ratio & -0.51 \\
Weaning weight & 0.31 \\
\hline
\end{tabular}

The Pearson correlations between the EBVs and GTVs ranged from -0.51 to 0.68 . The lowest correlation (closest to zero) was 0.26 between KLB and GTV. Correlations of 0.68 
and -0.51 were estimated between ADG and GTV and FCR and GTV, respectively. Although the correlations between GTV and ADG and between GTV and FCR are both moderate, an increase in GTV is expected with a higher ADG and lower FCR values. Figure 2 presents the genetic trend of the selection index value (GTV) and shows that there was an improvement in GTV over the years, but with fluctuation between years. The genetic improvement in GTV over the years could possibly be explained by the favorable correlations between GTV and FCR and GTV and ADG. The fact that breeders have selected for ADG and FCR in the past, together with these favorable correlations with GTV, could be an explanation for the genetic improvement of R1.55 per year (Figure 2) in GTV over the last 12 years.

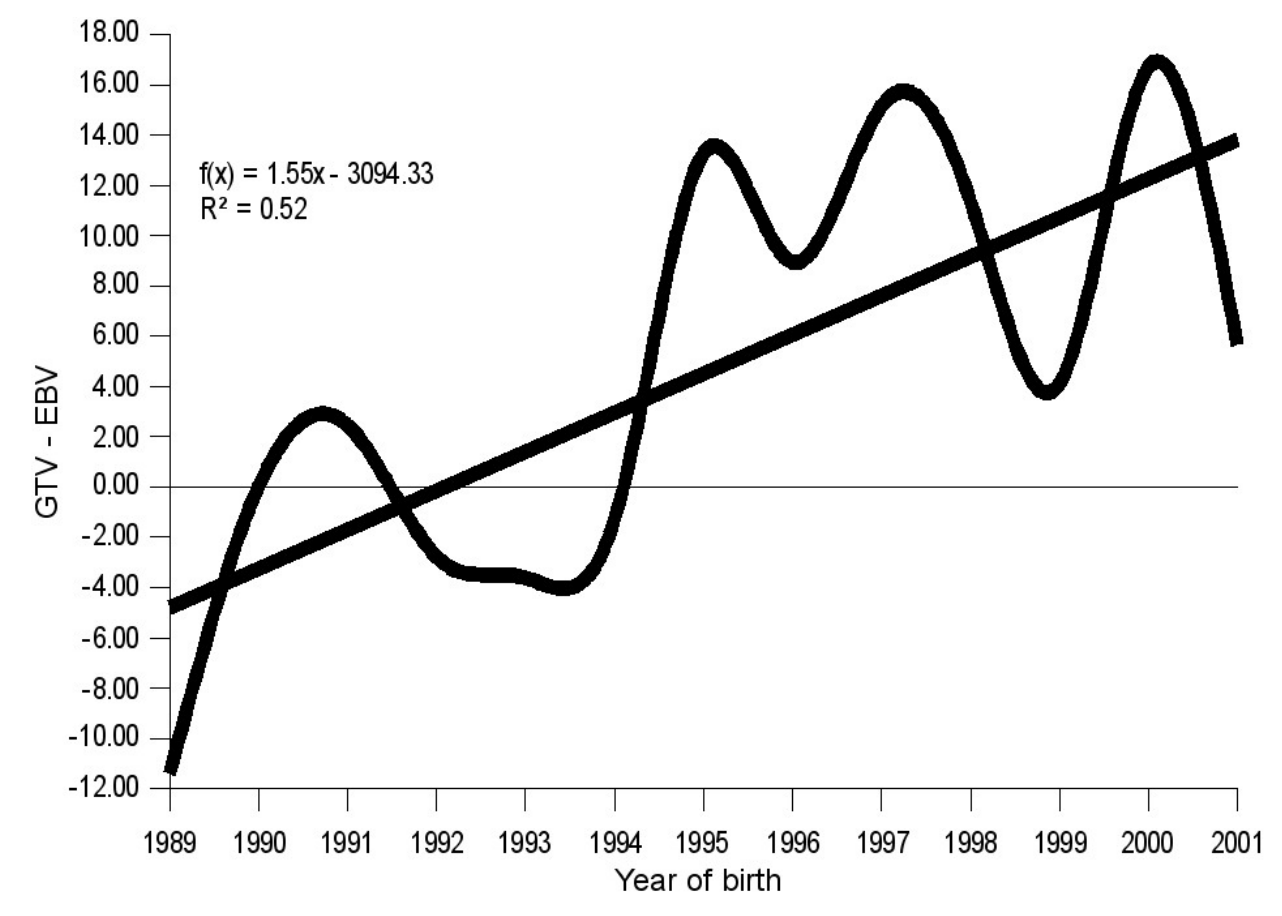

Figure 2. Genetic trend of the gross test value (GTV) selection index value. EBV = estimated breeding values.

\section{CONCLUSIONS}

It is possible to select for a post-weaning profitability or gross test profitability value (GTV). The selection index can benefit the feedlot industry by selecting offspring of bulls with high GTV values to maximize profitability in a feedlot or in a post-weaning growth test. It is recommended that such values should be provided in the analysis of centralized growth tests of beef bulls.

\section{REFERENCES}

Anonymous (1999). Beef Breeding in South Africa. Agricultural Research Council Animal Improvement Institute, Irene. Archer JA and Bergh L (2000). Duration of performance tests for growth rate, feed intake and feed efficiency in four 
biological types of beef cattle. Livest. Prod. Sci. 65: 47-55.

Archer JA, Arthur PF, Herd RM and Richardson EC (1998). Genetic Variation in Feed Efficiency and its Component Traits. In: Proceedings of the 6th World Congr. Genet. Appl. Livest. Prod., Armidale, 81-84.

Dickerson GE (1969). Experimental approaches in utilizing breed resources. Anim. Breed. Abstr. 37: 191-202.

Dickerson GE (1978). Animal size and efficiency: basic concepts. Anim. Prod. 27: 367-379.

Falconer DS and Mackey FC (1996). Introduction to Quantitative Genetics. 4th edn. Weslay Longman Limited, Edinburgh Gate, Harlow, Essex.

Ferrell CL and Jenkins TG (1984). Energy utilization by mature, nonpregnant, nonlactating cows of different types. $J$. Anim. Sci. 58: 234-243.

Groeneveld E (1994). VCE, a multivariate multimodel REML (co)variance component estimation package. In: Proceedings of the 5th World Congr. Genet. Appl. Livest. Prod., Guelph, 47-48.

Herd RM and Bishop SC (2000). Genetic variation in residual feed intake and its association with other production traits in British Hereford cattle. Livest. Prod. Sci. 63: 111-119.

Koots KR, Gibson JP, Smith C and Wilton JW (1994a). Analyses of published genetic parameter estimates for beef production traits. 1. Heritability. Anim. Breed. Abst. 62: 309-338.

Koots KR, Gibson JP and Wilton JW (1994b). Analyses of published genetic parameter estimate for beef production traits. 2. Phenotypic and genetic correlations. Anim. Breed. Abst. 62: 825-853.

Lerner IM (1961). The Genetic Basis of Selection. John Wiley and Sons, New York.

Nicholas FW (1987). Veterinary Genetics. Clarendon Press, Oxford.

SAS Institute (2000). SAS/STAT Users Guide, Version 8.02. SAS Institute, Cary.

Urick JJ, Pahnish OF, Richardson GV and Blackwell RL (1984). A comparison of crossbred and straightbred cow-calf pairs. I. Heterosis effects on total feed efficiency. J. Anim. Sci. 58: 1151-1159.

Van Oijen M, Monato-Bumudez M and Nielsen M (1992). Economic Efficiency of Herds Reserves of Milking Efficiency. Univ. of Nebraska, Beef Cattle Report, Lincoln.

Van Vleck LD (1993). Selection Index and Introduction to Mixed Model Methods. CRC Press, Boca Raton. 